\title{
Cardiovascular risk assessment - From individual risk prediction to estimation of global risk and change in risk in the population
}

\author{
John A Batsis 1,3 and Francisco Lopez-Jimenez*2
}

\begin{abstract}
Background: Cardiovascular disease is the most common cause of death and risk prediction formulae such as the Framingham Risk Score have been developed to easily identify patients at high risk that may require therapeutic interventions.

Discussion: Using cardiovascular risk formulae at a population level to estimate and compare average cardiovascular risk among groups has been recently proposed as a way to facilitate surveillance of net cardiovascular risk and target public health interventions. Risk prediction formulas may help to compare interventions that cause effects of different magnitudes and directions in several cardiovascular risk factors, because these formulas assess the net change in risk using easily obtainable clinical variables. Because of conflicting data estimates of the incidence and prevalence of cardiovascular disease, risk prediction formulae may be a useful tool to estimate such risk at a population level.

Summary: Although risk prediction formulae were intended on guiding clinicians to individualized therapy, they also can be used to ascertain trends at a population-level, particularly in situations where changes in different cardiovascular risk factors over time have different magnitudes and directions. The efficacy of interventions that are proposed to reduce cardiovascular risk impacting more than one risk factor can be well assessed by these means.
\end{abstract}

\section{Background}

\section{Prediction of CV risk}

As cardiovascular (CV) disease corresponds to the most common cause of death in the United States with estimates exceeding one million deaths annually [1], estimates of individual and population-based $\mathrm{CV}$ risk are of paramount importance. $\mathrm{CV}$ risk prediction formulae and tables are decision tools that allow the identification of patients at high risk of $\mathrm{CV}$ disease. These tools allow early interventions by providers to recommend lifestyle modification or drugs to control modifiable CV risk factors, including hypertension, diabetes, smoking, dyslipidemia and obesity.

Several CV risk prediction formulae are used in clinical practice worldwide. In the United States, the modified Framingham Risk Score (FRS) is the most commonly used tool [2], and has been adapted for use in diverse

\footnotetext{
*Correspondence: lopez@mayo.edu

2 Division of Cardiovascular Diseases, Department of Medicine, Mayo Clinic College of Medicine, 200 First Street SW, Rochester, MN 55905, USA

Full list of author information is available at the end of the article
}

populations in other parts of the world. Other tools include the Prospective Cardiovascular Munster Heart Study (PROCAM) [3], the Systematic Coronary Risk Evaluation system (SCORE) [4], United Kingdom Prospective Diabetes Study (UKPDS) [5] tool for diabetics, the Reynolds Risk Score [6,7] and more recently, one which includes obesity as a variable (NHANES) [8].

The variables included in the FRS include age, sex, smoking status, diabetes status, cholesterol, and blood pressure values. These variables are routinely available in patients receiving medical care, particularly in a primary care setting, as routine screening for hypertension, smoking status, dyslipidemia, and fasting hyperglycemia are part of normative preventative health measures [9]. With such information clinicians could either use gender-specific risk score tables in assigning points that can translate into a given 10-year CV risk, or use electronic or webbased risk calculators http://www.framinghamheartstudy.org/risk/coronary.html to calculate such risks. The purpose of risk stratification is to identify and treat patients that may be at higher long-term CV risk in a sim- 
ple and cost-efficient manner. This risk tool has an acceptable area under the receiver operating curve of roughly $75 \%[10]$. Most of these tools, particularly the FRS have been validated in many different populations and ethnic groups and recalibrated appropriately [11-14], making it a well-known risk index that allows comparison of risks across different population groups. However, there are distinct ethnic populations, particularly in those with higher prevalences of metabolic syndrome where recalibration is often challenging and its applicability may be limited [11,13-15].

The advent of other markers of $\mathrm{CV}$ disease, including high sensitivity C-reactive protein (HS-CRP), homocysteine, lipoprotein (a), or coronary calcification scores [16-18], have been shown to predict incident coronary disease but they add little prognostic value to standard risk formulae and their incorporation into present clinical practice has been challenging. High sensitivity CRP is associated with an increased risk of future cardiovascular disease, diabetes and even hypertension $[16,19,20]$. Yet studies have shown a minimal incremental value of adding new biomarkers to existing prediction models in a recent study by the Framingham group [21]. Interestingly, there is emerging evidence in potentially using CRP, particularly using the Reynolds Risk Score, to re-classify intermediate risk subjects into a high risk category for potential interventions $[6,7,22]$. In addition, detection of subclinical coronary artery disease with screening tests like $\mathrm{CT}$ to measure coronary calcium has been a topic of a recent debate. The AHA Consensus document which outlined the likely benefit of using this modality to riskstratify intermediate risk patients to either high or low categories depending on the score [23]. This group did not recommend its use in either low or high-risk patients. The utility of biomarkers for the detection of subclinical coronary disease for risk stratification may be limited in individuals believed to be at high CV risk, who for some reason have an FRS that is not too high, but these biomarkers are possibly useful in those with intermediate risk.

\section{Discussion}

Limitations of studies assessing the prevalence of coronary artery disease

The assessment of disease burden in the population is of critical importance for public health officials and health care policy makers. In the case of $\mathrm{CV}$ disease burden, there are some challenges to estimate changes in incidence and prevalence of $\mathrm{CV}$ disease. Although some epidemiologic studies have shown a downtrend in $\mathrm{CV}$ mortality in the USA [24-26], the trend in incident CV disease has demonstrated conflicting results [27]. Some of the problems are the change in diagnostic criteria for myocardial infarction, changes in screening patterns and improved diagnostic modalities to detect coronary and vascular disease in the subclinical phase, factors that will directly affect the likelihood to diagnose a person with CV disease.

Thus, estimates of change in CV risk may be meaningful and valid alternatives to assess trends in $\mathrm{CV}$ burden in the population. If $\mathrm{CV}$ risk prediction formulae have been shown to be accurate and useful in estimating risk at the individual level, they may also provide estimates of $\mathrm{CV}$ risk at the population level. The total $\mathrm{CV}$ risk in a population can be obtained by calculating the average $\mathrm{CV}$ risk using individual-based information on $\mathrm{CV}$ risk factors from nationally representative data like the National Health and Nutrition surveys (NHANES) and weighting it for standardized demographics [28].

The value of $\mathrm{CV}$ risk prediction formulae to estimate risk at the population level is also justified because $\mathrm{CV}$ risk factors have been constantly changing in different magnitude and direction over the past 30 years. For example, mean cholesterol values showed a downward trend soon after statins became widely available, but then flattened years later [29]. A similar trend was observed for cigarette smoking [29,30], while other factors like obesity [31,32] and diabetes mellitus [33-35] have become more prevalent. Furthermore, changes have not been uniform for both sexes and across different age strata. Because these major $\mathrm{CV}$ risk factors provide different strengths of risk for incident myocardial infarction [36], the only way to know the net trend in risk for incident CV disease in a given country may be by using risk prediction formulae.

A recent analysis examining changes in the predicted 10-year CV risk in the US, demonstrated that the estimated net risk for $\mathrm{CV}$ disease in the US population decreased between 1976 to 1980 and 1988 to 1994, but has changed minimally from 1988 to 1994 and from 1999 to 2004, particularly in women and middle-aged people [28]. These data have enormous public health implications, and suggest that the gain in primary prevention of CV disease that occurred from 1976 to 1980 and 1990 to 1994 has levelled off during the last time period, despite the discovery and implementation of effective treatment modalities in managing dyslipidemia and hypertension [37-39], national anti-smoking campaigns [40] and efforts related to primordial prevention. This study confirmed the utility of using simple risk-prediction tables or equations to project future CV risk and assess the trajectory of given trends. In addition, the same principle of usability of risk scores to assess population trends in predicted cardiovascular health may be also applied to newer scores attempting to predict lifetime CV risks [41]. In this study, aimed at predicting lifetime $\mathrm{CV}$ risk, the majority of participants (56\%) were classified as having a low short-term risk using the FRS. Indeed, using newer risk prediction 
rules that go beyond the typical 10-year horizon may have greater meaning for public health and public policy. Policy makers should be actively analyzing existing epidemiologic datasets in order to assess ongoing trends in net $\mathrm{CV}$ risk and to determine the areas with the highest yield to reduce $\mathrm{CV}$ risk in the population and plan for public health interventions.

\section{Estimation of net change in $\mathrm{CV}$ risk for interventions that affect risk factors in different ways}

Although pharmacologic interventions for either hypertension or dyslipidemia can induce a significant reduction in CV risk, lifestyle interventions that affect several risk factors are also a critical step in managing CV risk. Different lifestyle interventions lead to different levels of change in lipids, blood pressure, body weight and blood glucose, and therefore the net change in cardiovascular risk after implementing these interventions is rarely known. The comparison of different strategies in reducing $\mathrm{CV}$ risk is also problematic when they affect different $\mathrm{CV}$ risk factors in different ways. For example, very low fat diets can induce a reduction in body weight, blood pressure, and total and LDL cholesterol, but may also cause a reduction in HDL cholesterol. Mediterranean diets may improve weight, blood pressure and lipids, but cause HDL cholesterol to rise, although their effect on LDL may be more modest [42]. Diets like the dietary approaches to stop hypertension (DASH) also affect lipids, but their major benefit comes from blood pressure reduction, with limited effect on fasting glucose [43]. Thus, to ascertain which diet has a more favorable effect on $\mathrm{CV}$ events it is necessary to estimate and compare the net change in $\mathrm{CV}$ risk. Surprisingly, there have been limited studies examining the impact of either dietary modification or physical activity on 10-year predicted CV risk. Multiple studies have examined the impact of $\mathrm{CV}$ risk factor reduction following pharmacologic interventions, but very few have ascertained the net change in $\mathrm{CV}$ risk. Specifically, changes in Framingham risk with lifestyle intervention have not been extensively studied. One study demonstrated modest changes in FRS for primary prevention of $\mathrm{CV}$ disease using a health report card with counselling on cardiovascular risk factors [44]. The largest prospective trial to date recently evaluated a multicomponent lifestyle intervention demonstrating a relative risk of 0.88 (0.83 to $0.94 ; P<0.001)$ in patients undergoing an established lifestyle recommendation for blood pressure control (reduction in salt, weight loss, and physical activity) with a DASH diet, and 0.86 (0.81 to $0.91 ; P<$ $0.001)$ in the established lifestyle alone using the FRS [45].

\section{Estimation of events prevented with specific interventions}

Cardiovascular (CV) risk prediction formulae provide an estimated value that corresponds to the likelihood of developing $\mathrm{CV}$ events over a period of time. Thus, it could be argued that interventions that reduce the estimated risk would also result in a reduction in $\mathrm{CV}$ events. Two studies were published examining change in CV risk using both the FRS but also a risk score derived from the National Health and Nutrition Examination Surveys $[8,46]$. Using the FRS, the relative risk reduction for a cardiovascular event in patients managed surgically for obesity was $50 \%$, while all-cause mortality was reduced by $44.2 \%$ using the NHANES risk score. The 10-year risk did not change from $30 \%$ at baseline to $30 \%$ at follow-up in non-operative controls [8]. Such an intervention represents an estimate of 4 overall deaths and 16 cardiovascular events prevented by bariatric surgery per 100 patients compared with the non-operative group.

Other studies, using bariatric surgery cohorts, have used the FRS to estimate the CV risk reduction, and have demonstrated a relative risk reduction of $33 \%$ with an absolute reduction in FRS score from $6 \%$ to $4 \%(P<$ 0.001) [47]. Recently, two studies have examined the impact of bariatric surgery on long-term patient outcomes whose results parallel the outcomes predicted in the above studies. The Swedish Obesity study, whose study population consists primarily of vertical banded gastroplasty patients, had prospective patient data and the adjusted HR for death in the surgical group was 0.71 , suggesting a $29 \%$ less risk of death at 10-years in the surgical group [48]. In the study by Adams et al. [49], the adjusted long-term mortality was $40 \%$ lower in the surgical group with 7.1 years of follow-up. These results suggest that prediction tools like the FRS can potentially be practically used to estimate actual number of events in patients at higher cardiometabolic risk. We do caution, though, that further studies are needed to validate the use of such formulae in such select populations which may not be representative of the cohorts that the original formulae were developed from, to additionally incorporate disease-specific or procedure-specific complications in these assessments.

\section{Shortcomings of current risk prediction tools}

The FRS relies on traditional risk factors including hypertension, diabetes, smoking status, and dyslipidemia. Other risk factors like family history of premature $\mathrm{CV}$ disease, obesity, high sensitivity CRP, inflammatory cytokines and lifestyle are not incorporated in present risk formulae. By omitting these risk factors, the current risk prediction formulas may underestimate $\mathrm{CV}$ risk in some individuals, particularly those at intermediate $\mathrm{CV}$ risk $[6,7,22]$.

Accurate risk equations are often translated into risk tables to facilitate clinical decision making. Tables are used clinically to differentiate between high and low risk patients, allowing the implementation of preventative strategies. Thresholds are often used to categorize continuous variables as normal or abnormal or using differ- 
ent level proportional risk using a points system. By doing so, some prognostic information in extreme values is disregarded despite the linear or near linear association between $\mathrm{CV}$ risk factors and CV events. Variables whose incremental risk is proportional or exponential to its level, for instance, with hypertension or elevated LDL, the dichotomization of variables according to a given threshold leads to similar risks being applied to values that barely exceed the threshold with those that are far beyond the threshold. Conversely, values that are slightly below the threshold are often treated as normal, which leads to inaccuracies.

Sometimes, therapeutic interventions may have unintended consequences on other diseases, such as the increased mortality rates observed in diabetes with intensive insulin regimens [50]. The intent of such interventions is to improve cardiovascular risk factors which may not translate in a reduction in clinical events. In addition, other interventions, such as sodium restriction have larger effects on $\mathrm{CV}$ disease than its impact on blood pressure alone and modest effects yield greater than expected changes, which extend beyond such clinical markers [51]. This may limit the use of such prediction rules in forecasting trends in $\mathrm{CV}$ events using information related to changes in $\mathrm{CV}$ risk factors. Future scores should acknowledge and address these limitations.

However, further research is needed to be able to apply these risk prediction tools, intended for individualized patients, to translate into larger population-based health interventions. As the degree of cardiovascular and overall morbidity and mortality changes, the necessity of recalibrating existing risk equations is needed. For instance, the Framingham equation was based on a population of patients decades ago whose characteristics are much different than those existing nowadays [2]. In addition, with the development of new biomarkers and enhanced understanding of the pathophysiologic of atherosclerosis, future formulae will likely incorporate measures of factors representing different mechanistic pathways beyond the current approach that addresses traditional risk factors only. Hence, clinicians and public health officials need to be aware of the population-level estimates of disease burden to assess absolute risk. Furthermore, calibration needs to occur to allow application of risk algorithms to other population and/or ethnic groups. More importantly, risk prediction equations target preventative care to those asymptomatic patients at intermediate or high risk, but still roughly a third of all $\mathrm{CV}$ events occur in subjects labeled as low risk by common equations.

\section{Summary}

Risk prediction formulas were originally created for proper CV risk stratification at the individual level. They are recommended to guide medication therapy and iden- tify people in whom interventions may be more costeffective. The use of such risk prediction formulas in assessing risk trends at a population level may also be used to predict changes in net $\mathrm{CV}$ risk, potentially predicting changes in the incidence of $\mathrm{CV}$ disease and therefore may be used to preliminarily assess the trend in $\mathrm{CV}$ disease risk and burden in a particular population. These formulas can also be used to assess net benefit in $\mathrm{CV}$ risk reduction for interventions that can affect several $\mathrm{CV}$ risk factors such as diets with different macronutrient compositions that affect different $\mathrm{CV}$ risk factors, in different directions and magnitudes. Population-based estimates, though, can be guided by such formulae, understanding the caveat that not only calibration is needed when predicting risk in different populations, but also to consider the shortcomings due to imperfect prediction of clinical outcomes.

\section{Abbreviations}

CV: cardiovascular; FRS: Framingham risk score; HDL: high density lipoprotein; HR: hazard ratio; HS-CRP: high sensitivity C-reactive protein; LDL: low density lipoprotein; NHANES: National Health and Nutrition Examination Survey; PROCAM: Prospective Cardiovascular Munster Heart Study; SCORE: Systematic Coronary Risk Evaluation system; UKPDS: United Kingdom Prospective Diabetes Study.

\section{Competing interests}

The authors declare that they have no competing interests.

\section{Authors' contributions}

The authors contributed equally to the above manuscript in the conception, design, drafting and critically revising the manuscript, in addition to approving the final version.

\section{Author Details}

1Dartmouth Medical School, 1 Rope Ferry Road, Hanover, NH 03755, USA, 2Division of Cardiovascular Diseases, Department of Medicine, Mayo Clinic College of Medicine, 200 First Street SW, Rochester, MN 55905, USA and 3Section of General Internal Medicine, Department of Medicine, DartmouthHitchcock Medical Center, 1 Medical Center Drive, Lebanon, NH 03756, USA

Received: 29 April 2010 Accepted: 25 May 2010

Published: 25 May 2010

\section{References}

1. Rosamond W, Flegal K, Furie K, Go A, Greenlund K, Haase N, Hailpern SM, Ho M, Howard V, Kissela B, Kittner S, Lloyd-Jones D, McDermott M, Meigs J, Moy C, Nichol G, O'Donnell C, Roger V, Sorlie P, Steinberger J, Thom T, Wilson M, Hong Y, American Heart Association Statistics Committee and Stroke Statistics Subcommittee: Heart disease and stroke statistics-2008 update: a report from the American Heart Association Statistics Committee and Stroke Statistics Subcommittee. Circulation 2008, 117:e25-146.

2. Wilson PW, D'Agostino RB, Levy D, Belanger AM, Silbershatz H, Kannel WB: Prediction of coronary heart disease using risk factor categories. Circulation 1998, 97:1837-1847.

3. Assmann G, Cullen P, Schulte H: Simple scoring scheme for calculating the risk of acute coronary events based on the 10-year follow-up of the prospective cardiovascular Munster (PROCAM) study. Circulation 2002, 105:310-315.

4. Conroy RM, Pyorala K, Fitzgerald AP, Sans S, Menotti A, De Backer G, De Bacquer D, Ducimetiere P, Jousilahti P, Keil U, Njølstad I, Oganov RG, Thomsen T, Tunstall-Pedoe H, Tverdal A, Wedel H, Whincup P, Wilhelmsen L, Graham IM, SCORE project group: Estimation of ten-year risk of fatal cardiovascular disease in Europe: the SCORE project. Eur Heart J 2003, 24:987-1003. 
5. Stevens RJ, Kothari V, Adler Al, Stratton IM: The UKPDS risk engine: a model for the risk of coronary heart disease in Type II diabetes (UKPDS 56). Clin Sci (Lond) 2001, 101:671-679.

6. Ridker PM, Buring JE, Rifai N, Cook NR: Development and validation of improved algorithms for the assessment of global cardiovascular risk in women: the Reynolds Risk Score. JAMA 2007, 297:611-619.

7. Ridker PM, Paynter NP, Rifai N, Gaziano JM, Cook NR: C-reactive protein and parental history improve global cardiovascular risk prediction: the Reynolds Risk Score for men. Circulation 2008, 118:2243-2251. 2244p following 2251

8. Batsis JA, Romero-Corral A, Collazo-Clavell ML, Sarr MG, Somers VK, Brekke L, Lopez-Jimenez F: Effect of weight loss on predicted cardiovascular risk: change in cardiac risk after bariatric surgery. Obesity (Silver Spring) 2007, 15:772-784

9. Agency for Healthcare Quality Research: US Preventative Task Force [http://www.ahrq.gov/CLINIC/uspstfix.htm

10. Coleman RL, Stevens RJ, Retnakaran R, Holman RR: Framingham, SCORE, and DECODE risk equations do not provide reliable cardiovascular risk estimates in type 2 diabetes. Diabetes Care 2007, 30:1292-1293.

11. Brindle P, Emberson J, Lampe F, Walker M, Whincup P, Fahey T, Ebrahim S: Predictive accuracy of the Framingham coronary risk score in British men: prospective cohort study. BMJ 2003, 327:1267.

12. Haq IU, Ramsay LE, Yeo WW, Jackson PR, Wallis EJ: Is the Framingham risk function valid for northern European populations? A comparison of methods for estimating absolute coronary risk in high risk men. Heart 1999, 81:40-46.

13. Liu J, Hong Y, D'Agostino RB Sr, Wu Z, Wang W, Sun J, Wilson PW, Kannel WB, Zhao D: Predictive value for the Chinese population of the Framingham CHD risk assessment tool compared with the Chinese Multi-Provincial Cohort Study. JAMA 2004, 291:2591-2599.

14. Marrugat J, D'Agostino R, Sullivan L, Elosua R, Wilson P, Ordovas J, Solanas P, Cordon F, Ramos R, Sala J, Masiá R, Kannel WB: An adaptation of the Framingham coronary heart disease risk function to European Mediterranean areas. J Epidemiol Community Health 2003, 57:634-638.

15. Onat A, Ceyhan K, Basar O, Erer B, Toprak S, Sansoy V: Metabolic syndrome: major impact on coronary risk in a population with low cholesterol levels--a prospective and cross-sectional evaluation. Atherosclerosis 2002, 165:285-292.

16. Koenig W, Lowel H, Baumert J, Meisinger C: C-reactive protein modulates risk prediction based on the Framingham Score: implications for future risk assessment: results from a large cohort study in southern Germany. Circulation 2004, 109:1349-1353.

17. Koenig W, Khuseyinova N, Lowel H, Trischler G, Meisinger C: Lipoproteinassociated phospholipase $\mathrm{A} 2$ adds to risk prediction of incident coronary events by C-reactive protein in apparently healthy middleaged men from the general population: results from the 14-year follow-up of a large cohort from southern Germany. Circulation 2004 110:1903-1908.

18. Greenland P, LaBree L, Azen SP, Doherty TM, Detrano RC: Coronary artery calcium score combined with Framingham score for risk prediction in asymptomatic individuals. JAMA 2004, 291:210-215.

19. Freeman DJ, Norrie J, Caslake MJ, Gaw A, Ford I, Lowe GD, O'Reilly DS, Packard CJ, Sattar N: C-reactive protein is an independent predictor of risk for the development of diabetes in the West of Scotland Coronary Prevention Study. Diabetes 2002, 51:1596-1600.

20. Ridker PM, Buring JE, Shih J, Matias M, Hennekens CH: Prospective study of $\mathrm{C}$-reactive protein and the risk of future cardiovascular events among apparently healthy women. Circulation 1998, 98:731-733.

21. Wilson PW, Pencina M, Jacques P, Selhub J, D'Agostino R Sr, O'Donnell CJ: C-reactive protein and reclassification of cardiovascular risk in the Framingham Heart Study. Circ Cardiovasc Qual Outcomes 2008, 1:92-97.

22. Cook NR, Buring JE, Ridker PM: The effect of including C-reactive protein in cardiovascular risk prediction models for women. Ann Intern Med 2006, 145:21-29.

23. Greenland $\mathrm{P}$, Bonow RO, Brundage BH, Budoff MJ, Eisenberg MJ, Grundy SM, Lauer MS, Post WS, Raggi P, Redberg RF, Rodgers GP, Shaw LJ, Taylor AJ, Weintraub WS, American College of Cardiology Foundation Clinical Expert Consensus Task Force (ACCF/AHA Writing Committee to Update the 2000 Expert Consensus Document on Electron Beam Computed Tomography); Society of Atherosclerosis Imaging and Prevention; Society of Cardiovascular Computed Tomography: ACCF/AHA 2007 clinical expert consensus document on coronary artery calcium scoring by computed tomography in global cardiovascular risk assessment and in evaluation of patients with chest pain: a report of the American College of Cardiology Foundation Clinical Expert Consensus Task Force (ACCF/AHA Writing Committee to Update the 2000 Expert Consensus Document on Electron Beam Computed Tomography) developed in collaboration with the Society of Atherosclerosis Imaging and Prevention and the Society of Cardiovascular Computed Tomography. J Am Coll Cardiol 2007, 49:378-402.

24. Ford E, Giles W, Mokdad A: The Distribution of 10-Year Risk for Coronary Heart Disease Among US Adults. J Am Coll Cardiol 2004, 43:1791-1796.

25. Ford ES, Ajani UA, Croft JB, Critchley JA, Labarthe DR, Kottke TE, Giles WH, Capewell S: Explaining the decrease in U.S. deaths from coronary disease 1980-2000. NEngl J Med 2007, 356:2388-2398.

26. McGovern PG, Jacobs DR Jr, Shahar E, Arnett DK, Folsom AR, Blackburn H, Luepker RV: Trends in acute coronary heart disease mortality, morbidity, and medical care from 1985 through 1997: the Minnesota heart survey. Circulation 2001, 104:19-24.

27. Roger VL, Jacobsen SJ, Weston SA, Goraya TY, Killian J, Reeder GS, Kottke $T E$, Yawn BP, Frye RL: Trends in the incidence and survival of patients with hospitalized myocardial infarction, Olmsted County, Minnesota, 1979 to 1994. Ann Intern Med 2002, 136:341-348.

28. Lopez-Jimenez F, Batsis JA, Roger V, Brekke L, Ting HH, Somers VK: Trends in 10-Year Predicted Risk of Cardiovascular Disease in the United States, 1976 to 2004. Circulation Cardiovascular Quality Outcomes 2009 2:443-50

29. Carroll MD, Lacher DA, Sorlie PD, Cleeman Jl, Gordon DJ, Wolz M, Grundy SM, Johnson CL: Trends in serum lipids and lipoproteins of adults, 19602002. Jama 2005, 294:1773-1781.

30. Tobacco use among adults--United States, 2005. MMWR Morb Mortal Wkly Rep 2006, 55:1 145-1148.

31. Flegal KM, Carroll MD, Kuczmarski RJ, Johnson CL: Overweight and obesity in the United States: prevalence and trends, 1960-1994. Int J Obes Relat Metab Disord 1998, 22:39-47.

32. Ogden CL, Carroll MD, Curtin LR, McDowell MA, Tabak CJ, Flegal KM: Prevalence of overweight and obesity in the United States, 1999-2004. JAMA 2006, 295:1549-1555.

33. Geiss LS, Pan L, Cadwell B, Gregg EW, Benjamin SM, Engelgau MM: Changes in incidence of diabetes in U.S. adults, 1997-2003. Am J Prev Med 2006, 30:371-377

34. Harris ML, Eastman RC, Cowie CC, Flegal KM, Eberhardt MS: Comparison of diabetes diagnostic categories in the U.S. population according to the 1997 American Diabetes Association and 1980-1985 World Health Organization diagnostic criteria. Diabetes Care 1997, 20:1859-1862.

35. Harris MI, Flegal KM, Cowie CC, Eberhardt MS, Goldstein DE, Little RR, Wiedmeyer HM, Byrd-Holt DD: Prevalence of diabetes, impaired fasting glucose, and impaired glucose tolerance in U.S. adults. The Third National Health and Nutrition Examination Survey, 1988-1994. Diabetes Care 1998, 21:518-524.

36. Vasan RS, Sullivan LM, Wilson PW, Sempos CT, Sundstrom J, Kannel WB, Levy D, D'Agostino RB: Relative importance of borderline and elevated levels of coronary heart disease risk factors. Ann Intern Med 2005 , 142:393-402.

37. Expert Panel on Detection, Evaluation, and Treatment of High Blood Cholesterol in Adults: Executive Summary of The Third Report of The National Cholesterol Education Program (NCEP) Expert Panel on Detection, Evaluation, And Treatment of High Blood Cholesterol In Adults (Adult Treatment Panel III). JAMA 2001, 285:2486-2497.

38. Chobanian A, Bakris G, Black H, Cushman W: The Seventh Report of the Joint National Committee on Prevention, Detection, Evaluation, and Treatment of High Blood Pressure: The JNC 7 Report. JAMA 2003, 289:2560-2572.

39. Hajjar I, Kotchen TA: Trends in prevalence, awareness, treatment, and control of hypertension in the United States, 1988-2000. JAMA 2003, 290:199-206.

40. US Preventative Services Task Force: Counseling to Prevent TobaccoRelated Diseases: Recommendation Statement. Novermber 2003. Agency for Healthcare Research and Quality, Rockville, MD. [http:// www.ahrq.gov/clinic/uspstf/uspstbac.htm]

41. Marma AK, Berry JD, Ning H, Persell SD, Lloyd-Jones DM: Distribution of 10-year and lifetime predicted risks for cardiovascular disease in US adults: findings from the National Health and Nutrition Examination Survey 2003 to 2006. Circ Cardiovasc Qual Outcomes 2009, 3:8-14. 
42. de Lorgeril M, Salen P, Martin JL, Monjaud I, Delaye J, Mamelle N: Mediterranean diet, traditional risk factors, and the rate of cardiovascular complications after myocardial infarction: final report of the Lyon Diet Heart Study. Circulation 1999, 99:779-785.

43. Azadbakht L, Mirmiran P, Esmaillzadeh A, Azizi T, Azizi F: Beneficial effects of a Dietary Approaches to Stop Hypertension eating plan on features of the metabolic syndrome. Diabetes Care 2005, 28:2823-2831.

44. Wister A, Loewen N, Kennedy-Symonds H, McGowan B, McCoy B, Singer J: One-year follow-up of a therapeutic lifestyle intervention targeting cardiovascular disease risk. CMAJ 2007, 177:859-865.

45. Maruthur NM, Wang NY, Appel LJ: Lifestyle interventions reduce coronary heart disease risk: results from the PREMIER Trial. Circulation 2009, 119:2026-2031.

46. Batsis JA, Sarr MG, Collazo-Clavell ML, Thomas RJ, Romero-Corral A Somers VK, Lopez-Jimenez F: Cardiovascular risk after bariatric surgery for obesity. Am J Cardiol 2008, 102:930-937.

47. Vogel JA, Franklin BA, Zalesin KC, Trivax JE, Krause KR, Chengelis DL, McCullough PA: Reduction in predicted coronary heart disease risk after substantial weight reduction after bariatric surgery. Am J Cardiol 2007, 99:222-226.

48. Sjostrom L, Narbro K, Sjostrom CD, Karason K, Larsson B, Wedel H, Lystig T, Sullivan M, Bouchard C, Carlsson B, Bengtsson C, Dahlgren S, Gummesson A, Jacobson P, Karlsson J, Lindroos AK, Lönroth H, Näslund I, Olbers T, Stenlöf K, Torgerson J, Agren G, Carlsson LM: Swedish Obese Subjects Study. Effects of bariatric surgery on mortality in Swedish obese subjects. N Engl J Med 2007, 357:741-752.

49. Adams TD, Gress RE, Smith SC, Halverson RC, Simper SC, Rosamond WD, Lamonte MJ, Stroup AM, Hunt SC: Long-term mortality after gastric bypass surgery. N Engl J Med 2007, 357:753-761.

50. Gerstein HC, Miller ME, Byington RP, Goff DC Jr, Bigger JT, Buse JB, Cushman WC, Genuth S, Ismail-Beigi F, Grimm RH Jr, Probstfield JL, Simons-Morton DG, Friedewald WT: Effects of intensive glucose lowering in type 2 diabetes. N Engl J Med 2008, 358:2545-2559.

51. Cook NR, Cutler JA, Obarzanek E, Buring JE, Rexrode KM, Kumanyika SK, Appel LJ, Whelton PK: Long term effects of dietary sodium reduction on cardiovascular disease outcomes: observational follow-up of the trials of hypertension prevention (TOHP). BMJ 2007, 334:885-888.

\section{Pre-publication history}

The pre-publication history for this paper can be accessed here: http://www.biomedcentral.com/1741-7015/8/29/prepub

doi: 10.1186/1741-7015-8-29

Cite this article as: Batsis and Lopez-Jimenez, Cardiovascular risk assessment - From individual risk prediction to estimation of global risk and change in risk in the population BMC Medicine 2010, 8:29

Submit your next manuscript to BioMed Centra and take full advantage of:

- Convenient online submission

- Thorough peer review

- No space constraints or color figure charges

- Immediate publication on acceptance

- Inclusion in PubMed, CAS, Scopus and Google Scholar

- Research which is freely available for redistribution

Submit your manuscript at www.biomedcentral.com/submit
C Biomed Central 